\title{
A Foundation of Trust: The Key to China's Domestic Cosmetic Companies Earning Their Share of the Rapidly Expanding Chinese Cosmetics Industry
}

\author{
Xinyue Zhang \\ School of Ulink College of Beijing, Beijing 100009, China. \\ 2637289773@qq.com
}

\begin{abstract}
China is now the second largest consumer of cosmetics in the world behind the United States, and is continuing to expand rapidly. However, $80 \%$ of the cosmetics sold in China are imported from foreign companies - local Chinese cosmetic companies are finding it very difficult to gain market share in their own, domestic market. China's domestic cosmetics companies are confronted with many challenges: cultural issues of worshipping foreign products, claims of plagiarism and dishonest marketing and promotion, the significant expense of new product research and development. But, perhaps most significant of all, Chinese cosmetics customers worry about purchasing domestic products because there is an overall lack of trust that Chinese companies and their products will deliver on their brand's promise. In this article, I identify and discuss current issues of trust that Chinese consumers have with the domestic cosmetics industry, and suggest some strategic objectives for domestic cosmetic companies to follow towards reversing the dominance that foreign brands currently have over locally produced cosmetic products.
\end{abstract}

Keywords: China Cosmetics Industry; Lack of Consumer trust; Bloggers and Cosmetics Industry; Consumer Trust.

\section{China's Domestic Cosmetics Industry is Rapidly Expanding}

According to Euromonitor International (a global market research company specializing in industries, countries, and consumers) (DataMarket.com, 2018), China's cosmetics industry has dramatically increased in market size. From 2010 to 2016, its total sales improved from 2.45 billion CNY (356.7 million USD) to 3.33 billion CNY (484.8 million USD), an average annual compound growth rate of $8.52 \%$. China has now surpassed Japan to become the world's second-largest cosmetics consumer just behind the United States ("The beauty economy is fully awakened," 2018).

Since 2008 when China's per capita GDP (i.e., the total value of goods and services produced by China divided by China's total population) (Amadeo, 2018) exceeded 3,000 US dollars (20,792 CNY) for the first time, individual consumers no longer need to spend all of their money on food and clothing, and instead can make purchases toward pursuing a higher quality of life ("The Beauty Economy," 2018). In 2017, China's per capita GDP was last recorded as 15,308 US dollars, or about 106,000 CNY ("China GDP," 2018). This higher standard of living has contributed to the trend of Chinese consumers upgrading their cosmetics consumption compared to other types of consumer goods. China's core "cosmetics population" has soared from 22 million in 2005 to 100 million in 2010 and is expected to reach 400 million by 2020. From 2012 to 2016, the compound annual growth rate of the cosmetics market was 11.8\% ("The Beauty Economy," 2018).

China's top five domestic cosmetics categories with respect to sales are: skin care products, hair care products, oral care products, bath products, and make-up. Skin care products is the largest subgroup, accounting for $50.7 \%$ of the overall domestic cosmetics market in 2016 ("The Beauty Economy," 2018).

Five years ago, most Chinese who wear make-up were only familiar with foreign brands (e.g., NARS, KAT VON D, BECCA, MAC, or other foreign luxury products). Today, many Chinese companies are entering the marketplace, with some gaining market share, as they become increasingly known by greater numbers of the population. However, foreign brands still dominate China's cosmetics market; and the main issue is trust. Too many domestic consumers of cosmetics do not trust that Chinese brand cosmetics will meet the promises of their advertising. 


\section{Bloggers and Trust in China's Domestic Cosmetics Industry}

In order to make their products more widely known by potential buyers, cosmetics firms often choose to advertise their products by sponsoring bloggers (individuals who use social media to share their own experiences, observations, and opinions). Companies ask bloggers to promote their company's products in their posts. For example, a blogger might recommend a company's product as a "monthly favorite," such as a sponsored facial cleanser, explaining which product is suitable for oily skin, dry skin, sensitive skin, or suitable for all types of skin - unfortunately, bloggers will often exaggerate a product's abilities or function in order to promote company sales.

These days, Chinese consumers are very aware of such product exaggeration in marketing and promotion. If a blogger recommends a domestic cosmetics product, negative comments will occur. For example, a few months ago, three or four bloggers I follow all recommended Perfect Diary eyeshadow. Perfect Diary is a domestic brand that I have bought before, the quality of their product is quite good, and their color-matching is suitable for daily makeup. The bloggers that recommended this eyeshadow made sense to me because of its high quality and appropriate pricing; the price of Perfect Diary's eyeshadow is much cheaper than its international competitors, although its product has the same quality and color-matching. However, every blogger who recommended Perfect Diary's eyeshadow received bad comments; e.g., "This is definitely a sponsored product," "It's so obvious this girl is just pretending that she likes it," and so on. The previous negative experiences by Chinese consumers with domestic cosmetics have resulted in their loss of trust, and now they will not even give high quality domestic products a chance.

\section{Lack of Trust in Domestic Celebrity Branding of China's Domestic Cosmetics}

Chinese consumers rarely trust products marketed and promoted by celebrities. For example, Zhang Mofan - better known as MOMO - has nearly 8 million followers on Weibo, she decided to create her own skin care brand: Mo. amour. These days, many Internet celebrities open their own TAOBAO (online shopping) stores to sell products, with the vast majority selling their own brand of clothes. Unfortunately, the majority of these clothing brands have bad reputations because so many of the products they sell are direct copies of famous foreign brands (such as Gucci and Dior); and they are very poor quality. The unsatisfactory experiences of so many online shoppers have damaged the trust that Chinese consumers have with many domestic products.

In this case of MOMO's Mo. amour, netizens on Weibo were highly critical of MOMO's facial mask, toner, and other skin care products, and would often leave negative comments such as: "Never trust celebrity's brand, it will destroy you face!" or "Don't ever trust her! Don't buy it." However, I am a big fan of Mo. amour, especially the toner, which has worked really well toward solving acne problems on my face - it's very helpful! Unfortunately, so many netizens don't believe in its quality.

I think the people who leave these negative comments have never even tried Mo. amour. In fact, this prejudgment of Chinese domestic brands occurs too frequently. MOMO's Mo. amour has been victimized by the previous bad experiences online shoppers have had with Chinese domestic brands, especially celebrity brands.

The management of Chinese domestic cosmetic companies need to recognize the predisposition that today's Chinese consumers have towards domestic cosmetic brands. Chinese companies need to craft a strategy to earn back local consumer trust, execute the strategy, and then evaluate their performance, making corrective adjustments where necessary.

\section{Why So Little Trust in China's Domestic Cosmetic Brands?}

Seeking to identify the primary reasons that Chinese consumers lack trust in Chinese domestic cosmetics, I initiated a Weibo-based survey to learn from my peers about their cosmetics buying experiences. In addition, I interviewed bloggers sponsored by domestic cosmetics companies, 
workers selling Chinese cosmetics in local retail stores, and a principal shareholder of HEDONE, a domestic Chinese cosmetics company.

From my survey-based research, I identified four main issues that contributed to a lack of trust in Chinese domestic cosmetic brands: 1. lack of innovation / plagiarism; 2. placing short-term gains over long-term customer development; 3. lack of truth in advertising; 4. poor after-sales customer service.

Too many Chinese brands that produce eyeshadow palettes and lipstick packaging directly copy foreign brands, or introduce only a few minor changes in their product offering. This, accompanied with consumers' online shopping experiences with poor product quality, and the general feeling is that Chinese brands plagiarize, leading consumers to choose foreign brands over Chinese brands.

There is a sense that Chinese brands are more interested in making short-term financial gains instead of developing long-term relationships with Chinese consumers. Such companies do not put their customers first; instead they sell poor quality products, make quick money, and are not concerned with repeat sales. This frustrates Chinese consumers and, unfortunately, contributes to the overall bad reputation for all Chinese domestic brands.

\section{Building Trust Between Consumers and Producers}

Building trust between a consumer and producer must be a consistent process throughout the management of a business. A key focus for companies should always be to build trust and loyalty with consumers, this is an essential part of building long-term relationships with customers. Today, domestic consumers have a high-level of mistrust with China's domestic cosmetics industry. Only if companies deliver on the promise of their products as advertised, are they going to have consumer loyalty in the long-term.

For example, if a cosmetics company produces a foundation (make-up applied to the face to create a uniform color to the complexion), promotes in its advertising that it can last for 12 hours, and that its ingredients will not cause breakouts (acne and pimples), its product needs to match what its advertising claims. If, on the other hand, the foundation only lasts for 8 hours, and causes some of its consumers to breakout, then the cosmetics company did not deliver on its advertising promise — this creates a lack of trust with the cosmetics company.

As a case study, I have tried many, many, make-up foundations, and $90 \%$ of them promise that they can last for 10 hours or longer, but only Estée Lauder Double Wear foundation achieved what was promised in their advertising. When it comes to establishing trust with consumers, the bottom line is the stability of the product: 1 . What is the stability of product excellence and quality; 2 . Is product price appropriate given its quality; and 3. Does the company offer effective customer service after the sale of the product?

If a Chinese domestic cosmetics company states that their make-up foundation lasts for 12 hours, and it doesn't damage the skin, even if at first domestic consumers might not trust this company due to previous experiences thereby resulting in prejudgment and negative comments via social media over time, the positive reviews from customers who have experienced the high quality product will not only gain the consumer trust, but will also build consumer loyalty and repeat sales.

\section{A Conversation with HEDONE Cosmetics}

In my conversation with a principal shareholder of HEDONE, a woman-owned business, I learned a lot about the realities that China's domestic cosmetics companies have to face. Trends in the beauty industry change quickly, and it takes a lot of money for domestic companies to remain in step with current styles of product packaging for lipstick, eyeshadow color palettes, etc. And if these companies do not act quickly, they will miss the market opportunity.

It is also difficult for China's smaller domestic companies to attain the same popularity as mature and often much larger, foreign companies. Smaller companies have little ability to lead market trends and, therefore, can only follow the fashion trends established by big brands. As a result, plagiarism 
is often a reflection of the helplessness that many domestic cosmetic companies feel in the marketplace.

Culture is also a huge challenge for domestic companies. China is not the only country where consumers seem to worship foreign brands. That is, all things considered, if the quality of domestic brands were equal to foreign brands, and even if the price was lower than foreign brands, Chinese consumers will still choose foreign products. Or, if the price of domestic brands were equal, and the domestic brand's quality was better than the foreign brand, domestic consumers would still be skeptical of domestic Chinese products; again, they would choose foreign brands.

Not long ago, HEDONE released a lip-gloss to the marketplace that was inspired by "the seven deadly sins" ("Hedone Seven Sins," 2018). Many Chinese consumers posted negative comments on social media related to HEDONE "copying other brands" because previous foreign products have been inspired by these famously impish behaviors (i.e., pride, greed, lust, envy, gluttony, wrath and sloth). However, when NARS, a well-known French cosmetics company announced that it was producing a line of lipstick inspired by the seven deadly sins ("7 Deadly Sins," 2018), virtually no Chinese netizens criticized NARS about their product plagiarism.

In the Chinese domestic cosmetics industry, this is the sales environment that new company manager's must face. Not only do they face cultural realities that favor foreign brands, they must also confront historical issues related to consumer trust.

\section{Summary}

It is difficult to become a successful business, especially in an industry where foreign brands already hold such a competitive advantage; this is the case with China's domestic cosmetics industry. The costs of entering the cosmetics marketplace is high, and many start-ups do not have the financial capital to support the necessary research and development, original product design, packaging, or even experienced personnel, let alone robust customer service. These issues are exacerbated in a market environment where the average Chinese consumer lacks trust in domestic brands - smaller domestic companies find it extremely difficult to gain market share against the much larger and more established foreign brands.

Managers of Chinese cosmetics companies need to craft a strategy to earn back Chinese consumer trust if they are to have any chance of gaining a significant market share of the rapidly expanding domestic cosmetics market, and they need to work harder to appeal to the needs of Chinese consumers. Consumers historical experiences with plagiarism, sponsored bloggers, and celebrity marketing and promotion, now leads to negative postings on social media even when recent domestic cosmetic products, in my experience, are of high quality.

Managers must learn from and take seriously the posts of their target customers, who worry about product exaggeration in advertising, or worse, products that will harm their skin.

And what would the managers learn from Chinese customers of domestic cosmetics, like me? They seek product reliability, honesty in advertising, and product consistency over time (Smale, 2017). If managers follow a strategy that embraces these principles, I am confident that Chinese domestic cosmetic companies will, in time (this will not happen overnight) earn the trust of Chinese consumers and, in turn, get their share of the rapidly expanding Chinese domestic cosmetics market

\section{References}

[1]. Amadeo, Kimberly. (2018, August 13). "GDP Per Capita with its Formula and Country Comparisons." Retrieved from https:/www.thebalance.com/gdp-per-capita-formula-u-scompared-to-highest-and-lowest-3305848.

[2]. "China GDP per capita PPP." (2018). Trading Economics. Retrieved on October 8, 2018 from https://tradingeconomics.com/china/gdp-per-capita-ppp. 
[3]. Davis, Steve. (2017, June 30). "How do brands build trust with consumers?" Retrieved from https://bakermarketingservices.com/2017/06/brands-build-trust-consumers.

[4]. Euromonitor. (2018). DataMarket.com. Retrieved on October 7, 2018, from https:// datamarket. com/data/list/?q=provider\%3Aeuromonitor.

[5]. Feng Huangwang. (2017, March 14). "Cosmetics Product Marketing That Catches Our Attention." Retrieved from http://wap.zdface.com/1/771/356324.html.

[6]. Smale, Thomas. (2017, February 15). "5 Strategies for How to Make Customers Trust Your Brand." Retrieved from https://www.entrepreneur.com/article/289167.

[7]. "The Beauty Economy is Fully Awakened." [Meili jingli quanmian juexing huazhuangpin guohuo jueqi zhengdangshi]. (2018, May 17). Retrieved from http:// news. cnstock. com/paper, 2018-05-17,997941.htm.

[8]. Lackey, Meredith. (2018, February 27). Chinese Internet Celebrities Attract Global Following. Retrieved from http://en.cifnews.com/chinese-internet-celebrities-attract-global-following/.

[9]. Galbraith, Barb. (2016, May 9). "Building Trust from Producer to Consumer." Manitoba Cooperator. Retrieved from https://www.manitobacooperator.ca/comment/building-trust-fromproducer-to-consumer/.

[10]. “7 Deadly Sins Audacious Lipstick Palette.” (2018). Retrieved on October 10, 2018 from https://www.narscosmetics.com/USA/7-deadly-sins-audacious-lipstick-palette/0607845084723. html.

[11]. "Hedone Seven Sins lip gloss red bean milk tea color plum brown black lip Color Lip Gloss." (2018). Retrieved on October 10, 2018 from https://www.yoycart.com/Product/574075256876/. 